\title{
Practical Challenges of Creating and Managing the "Barrier-Free Basic Plan" for Better Accessibility in Cities by Local Governments in Japan
}

\author{
Maiko SUGAWARA $^{\mathrm{a}, 1}$, Hirokazu NAGANO $^{\mathrm{b}}$, Tomoya BEPPU $^{\mathrm{c}}$ \\ and Tomoyuki INAGAKI ${ }^{\mathrm{d}}$ \\ ${ }^{\mathrm{a}}$ Toyo University, ${ }^{\mathrm{b}}$ Fukushima University, \\ ${ }^{\mathrm{c}}$ Yachiyo Engineering Co., Ltd., ${ }^{\mathrm{d}}$ Chuo University
}

\begin{abstract}
The Barrier-Free Basic Plan (BFBP) of Japan is based on Article 25 in the Act on the Promotion of Smooth Transportation, etc. of Elderly Persons, Disabled Persons, etc., abbreviated as the "Barrier-Free Act". BFBPs are created by municipal governments and play a crucial role in progressing the accessibility of existing buildings/facilities in cities. However, the number of municipal governments which have their own BFBPs stands at only 304 out of a total of approximately 1700 municipalities in 2020. The purpose of this paper is to describe the barriers and difficulties that administrative officers face in creating and managing BFBPs. The questionnaires were distributed in 2018 to 183 municipal governments which have their own BFBPs. The procedures of analyzing the results were as follows: 1) motivation for creating their own BFBPs, 2) supportive advisers in proceeding with the creation of BFBPs, 3) difficulties of creating their own BFBPs, 4) key factors promoting the quality of BFBPs, and 5) self-evaluation of their own BFBPs. In conclusion, the challenges that administrative officers faced in creating BFBPs and the required measures to raise the quality of BFBPs on a practical level were discovered, by considering the population scales of municipalities and the establishment year of the BFBP. The continuous removing of obstacles in existing buildings based on BFBPs will allow for more comfortable and accessible cities for everyone.
\end{abstract}

Keywords. Accessible cities, Barrier-Free Act, Municipal governments, Universal Design

\section{Introduction}

\subsection{What is the Barrier-Free Basic Plan in Japan?}

The Barrier-Free Basic Plan (BFBP) of Japan is based on Article 25 in the Act on the Promotion of Smooth Transportation, etc. of Elderly Persons, Disabled Persons, etc., abbreviated as the "Barrier-Free Act". Municipal governments can create their own BFBPs which aim to make accessible cities for everyone.

${ }^{1}$ Corresponding Author, Maiko Sugawara, Department of Human Environment Design, Faculty of Life Design, Toyo University, 48-1, Oka, Asaka-shi, Saitama, 351-8510, Japan; E-mail: sugawara@toyo.jp 
Japanese legislation for improving accessible cities has progressed since 1994. Previously, there were many grass-roots movements by citizens, and various measures were established by some advanced municipal governments to promote the living environment and the well-being of people with disabilities [1]. These struggles and challenges led to the Act on Buildings Accessibility and Usable by the Elderly and Physically Handicapped in 1994. However, this act only referred to buildings and provided accessibility to people with physical disabilities, but not those with mental or intellectual disabilities. In 2000, the Act on Promoting Easily Accessible Public Transportation Infrastructure for the Aged and the Disabled was enacted. This act targeted transportation infrastructure and all disabilities. The original BFBP was introduced through this act, although it only covered public transportation facilities. As a result, these acts were integrated in 2006, which is referred to as the Barrier-Free Act. Based on this new act, municipal governments and residents started to discuss the accessibility of both buildings and transportation methods in their own cities by involving professionals in the fields of architecture, city planning, and civil engineering. The renewal of the BFBP also expanded its scope.

Specifically, under the Barrier-Free Act, train stations with a daily average of more than 3,000 passengers should provide step-free access for passengers with reduced mobility and fall prevention fences on platforms for people with visual disabilities. In addition, specific types of new buildings over $2000 \mathrm{~m}^{2}$ must follow the Barrier-Free regulations to guarantee accessibility.

However, the promotion of the accessibility of existing buildings and facilities that are not mandated to follow these regulations is a challenge not only for Japan but also for many other countries. Thus, municipal governments can establish councils to discuss the current barriers of existing buildings/facilities by involving the public, so that residents including old people and people with disabilities can have the opportunity to express their opinions regarding mobility-related obstacles in their daily lives. Following the discussions, municipal governments can create their own BFBPs with the involvement of the public and experts. The expense of creating/managing BFBPs is partly supported by the national government.

In their own BFBPs, municipal governments can determine "ConcentratedDevelopment Districts" which include busier train stations, bus terminals, or government facilities for daily use. The facilities in these districts are usually within walking distance from each other. In these districts, municipal governments can ensure that public/private sectors managing buildings and transportation facilities plan and carry out projects that facilitate better accessibility (BF projects). In addition, these sectors can partially gain financial support from the national government to conduct their own BF projects. Consequently, the accessibility of existing buildings and facilities is being selectively and integrally improved to ensure all residents can enjoy walking and living comfortably in central areas of their own cities without any environmental barriers. Therefore, this will lead to a more universal design of cities.

The words "Barrier-Free" and "Universal Design" have often been used in official documents, academic fields, and mass media; thus these two words have become common among the citizens of Japan.

\subsection{Current status and issues of BFBPS}

Accordingly, 200 out of a total of approximately 1700 municipal governments created their own BFBPs between 2000 and 2006 [2]. In 2020, the current number of 
municipal governments with their own BFBPs stands at only 304 (approximately 17\%) [3]. The main reason why the increase in BFBPs has remained marginal is that "making an effort" to create BFBPs (but not actually creating them) is mandatory for municipal governments. The act is not legally enforceable, so the municipal governments do not always create them.

On the other hand, there have been some recent developments and trends regarding accessibility in Japan. In 2013, the Tokyo Metropolitan Government won the right to host the Olympics and Paralympics in 2020, which led to a new trend in the following way; the Japanese government ratified the UN Convention on the Rights of Persons with Disabilities (CRPD) in 2014, and the CRPD also had a big impact on Japanese society. Furthermore, the Act for Eliminating Discrimination against Persons with Disabilities came into force in 2016. The CRPD and the 2020 Games have driven Japan to improve its accessibility policies. As part of the policies, the Barrier-Free Act was amended in steps, between 2018 and 2020 [4].

According to this amendment, municipal governments can create BFBPs as well as barrier-free master plans and barrier-free maps while obtaining new subsidies from the national government. However, it is unpredictable how many municipal governments will create their own BFBPs after this amendment which is not legally enforceable. In addition, there has been insufficient analysis on the slow-down of the spread of BFBPs as described in the literature review. Although the Ministry of Land, Infrastructure, Transport and Tourism (MLIT) annually conducts investigations of municipal governments to illustrate the status and characteristics of BFBPs [5].

This paper describes the barriers and difficulties that the administrative officers face in creating BFBPs and the factors that are required to raise their quality on a practical level. This survey was conducted in 2018 during the amendment of the Barrier-Free Act. Thus, this research will also compare the status and problems of BFBPs approximately five years after the amendment.

\section{Literature Review}

In Japan, various articles have been published regarding the Barrier-Free and Universal Design of transportation, buildings, and rooms such as bathrooms, restrooms, baby care rooms and so forth in the fields of civil engineering, urban engineering, rehabilitation engineering and architecture. This section mainly describes the background of the research on BFBPs which was initiated in 2000.

Fujimura [6] focused on 15 advanced municipal governments that created BFBPs within one and a half years after the enforcement of the BFBP system. He described its early features and the difficulties of managing BFBPs by the municipal governments. Suzuki [7] highlighted the public involvement in BFBPs and demonstrated how to actively involve the general public through a case study of Himeji City. Using a quantitative analysis, Yamada [8] comprehensively revealed the problems regarding administration management and workshops as the public involvement method through questionnaires to 147 municipal governments that had their own BFBPs as of July 2004. They pointed out that the process of gaining the corporation of various residents and the private sector for workshops consequently made administrative officers improve their knowledge and skills. The efforts of these advanced municipal governments [6] [7] [8] were beneficial for other municipal governments that intend to create their own BFBPs. 
After the enforcement of the Barrier-Free Act in 2006, Isobe [9] realized that the increase of municipal governments that created their own BFBPs began to slow down. He participated as a BFBP expert in four municipal government councils to create BFBPs. He illustrated the difficulties faced by these municipal governments and proposed flexible methods to address them. However, the effectiveness of his proposals has not been inspected at a practical level and, thus, are rather limited. Fujiwara [10] examined the progress of the BF projects and the remaining issues from a case study of Osaka City in terms of the effectiveness of their BFBP. He also indicated the importance of the PDCA cycles of BFBP. Sato et al. [11] defined the difficulties of improving the accessibility of large-scale train stations that were located on the borders of neighboring cities. Furthermore, Ishizuka [12] investigated the continuous public involvement method applied in carrying out the PDCA cycles of BFBPs. She clarified from three advanced municipal governments that there were three stages of continuous public involvement: 1) the preliminary and planning stage, 2) the most active stage and 3) the standardization and stable stage. Further, she figured out that providing opportunities to participate in BFBPs, especially in the third stage, was especially important. Thus, these articles [9] [10] [11] [12] revealed the characteristics and problems after 2006, however all of them were case studies.

The MILT usually conducts a yearly survey with all municipal governments to understand the features of the management and progress in creating BFBPs [13]. The results are open to the public. However, they only provide basic information and have not been analyzed at an academic level.

Through a quantitative analysis, this research discovers the methods of overcoming the difficulties faced by the municipal governments when creating their own BFBPs, which will eventually lead to accessible cities for all.

\section{Methodology}

The questionnaire was conducted with 294 municipal governments, all of whom had their own BFBPs since March 2017 (Table 1). The number of valid responses was 183 $(62.2 \%)$.

Table 1. Locations of the survey subjects

TN: Target Number RN: Response Number

\begin{tabular}{l|r|r|l|r|r|l|r|r}
\hline $\begin{array}{l}\text { Prefectural } \\
\text { District }\end{array}$ & TN & RN & $\begin{array}{l}\text { Prefectural } \\
\text { District }\end{array}$ & TN & RN & $\begin{array}{l}\text { Prefectural } \\
\text { District }\end{array}$ & TN & RN \\
\hline Hokkaido & 14 & 11 & Ishikawa & 1 & 1 & Okayama & 2 & 2 \\
\hline Aomori & 1 & 1 & Fukui & 2 & 1 & Hiroshima & 9 & 4 \\
\hline Iwate & 2 & 1 & Yamanashi & 4 & 3 & Yamaguchi & 3 & 1 \\
\hline Miyagi & 1 & 1 & Nagano & 4 & 1 & Tokushima & 1 & 1 \\
\hline Akita & 1 & 1 & Gifu & 13 & 5 & Kagawa & 2 & 1 \\
\hline Yamagata & 2 & 0 & Shizuoka & 13 & 9 & Ehime & 2 & 1 \\
\hline Fukushima & 4 & 1 & Aichi & 9 & 7 & Kochi & 1 & 1 \\
\hline Ibaraki & 7 & 5 & Mie & 5 & 2 & Fukuoka & 10 & 6 \\
\hline Tochigi & 7 & 4 & Shiga & 12 & 7 & Saga & 1 & 0 \\
\hline Gunma & 3 & 2 & Kyoto & 10 & 7 & Nagasaki & 2 & 2 \\
\hline Saitama & 10 & 6 & Osaka & 33 & 25 & Kumamoto & 1 & 1 \\
\hline Chiba & 14 & 8 & Hyogo & 9 & 6 & Oita & 2 & 2 \\
\hline Tokyo & 29 & 22 & Nara & 6 & 3 & Miyazaki & 1 & 0 \\
\hline Kanagawa & 17 & 11 & Wakayama & 5 & 1 & Kagoshima & 1 & 0 \\
\hline Niigata & 9 & 5 & Tottori & 3 & 3 & Okinawa & 1 & 0 \\
\hline Toyama & 2 & 0 & Shimane & 3 & 1 & Total & 294 & 183 \\
\hline
\end{tabular}


The procedures of analyzing the results were as follows: 1) motivation for creating their own BFBPs, 2) supportive adviser in proceeding with the creation of BFBPs, 3) difficulties of creating their own BFBPs, 4) key factors promoting the quality of BFBPs, and 5) self-evaluation of their own BFBPs.

In addition, these results would differ according to the population scale of municipal governments and the establishment year of BFBPs. Therefore, 183 municipal governments were classified into the following five groups by the combination of their population scale and BFBP establishment year (Figure 1).

For the population scale, the respondents were divided into two groups based on population, under or over 200,000 , by considering the Japanese urban planning system. A population of over 200,000 municipal governments can be ordinance-designated cities and have the authority to manage some of their own issues in place of prefectural governments. Thus, the respondents with a population of over 200,000 include some ordinance-designated cities, despite the current population of some of these cities being under 200,000.

Regarding the establishment year of BFBPs, they were divided into the following three groups: a) the BFBP was created before 2006 and has not been renewed yet, b) the BFBP was created before 2006 and renewed after 2006, and c) the BFBP was created after 2006. Figure 3 shows the composition and relation of the five groups. However, Sc is composed of 20 municipal governments with populations of under 200,000 and 6 over 200,000 to conduct a comparative analysis between the groups with a sufficiently large parameter. Therefore, the characteristics of results 1) - 5) are revealed in each group.

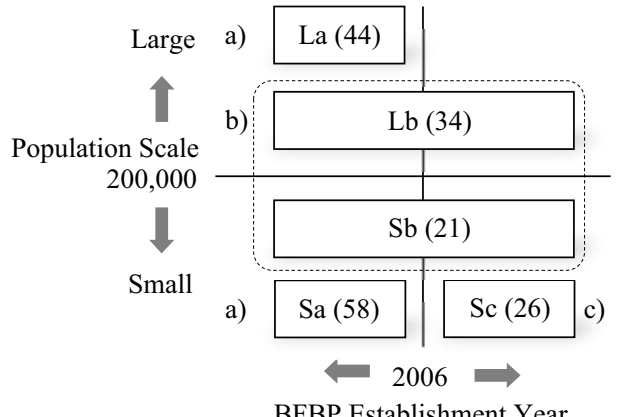

The features of the five groups;

La; over 200,000 people/established before 2006

Lb: over 200,000 people/renewed after 2006

Sa: under 200,000 people/established before 2006

Sb: under 200,000 people/renewed after 2006

Sc: under 200,000 people/established after 2006

(n); Parameter

Figure 1. Classification of respondents in terms of population scale and BFBP establishment year

\section{Results}

\subsection{Motivation for creating their own BFBPS}

Figure 2 summarizes the results regarding their motivation for creating their own BFBPs. There were 12 options, and the respondents could select up to three options. Regarding the three most selected options, the first one was "Enforcement/Amendment Act" (60.1\%), the second "Obtaining subsidies" (26.8\%), the third "Relation with upper 
urban political plans" $(26.2 \%)$. This implies that the main motivations are derived from national and municipal policies rather than their residents' direct demands, as can be observed from the low rate $(13.1 \%)$ of "Residents' demands".

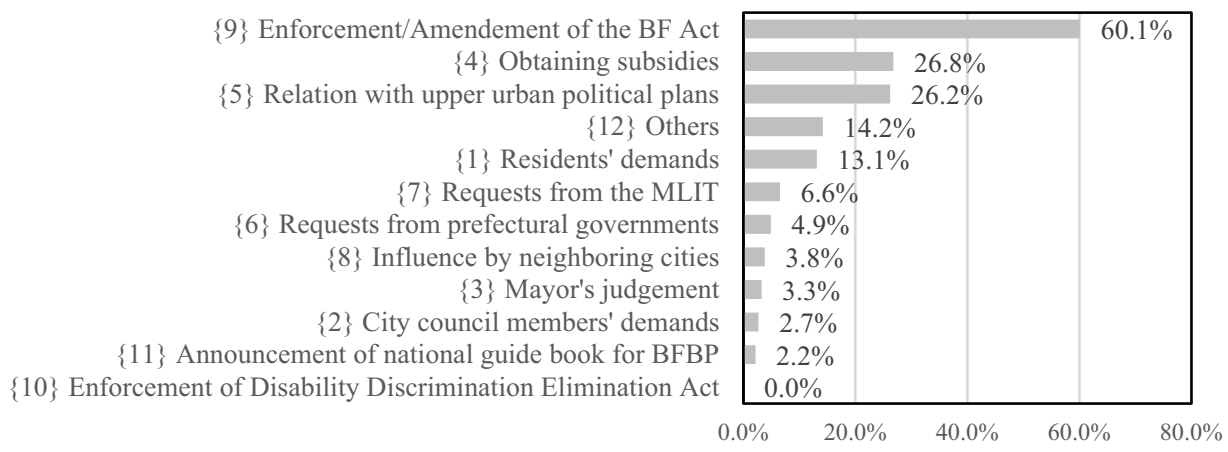

Figure 2. Percentages of the selected options among all respondents (selected up to three)

Regarding the features of each group (Table 2), the highest percentage of the selected options was "Enforcement/Amendment Act" for all groups except Sc. In particular, this strong tendency can be observed in Group L (La, Lb), which are largescale municipalities. On the other hand, the percentages of "Obtaining subsidies" of Sa, $\mathrm{Sb}$, and especially $\mathrm{Sc}$, all which were small-scale municipalities, were considerably higher than those of Group L.

In addition, the third highest percentage of Lb was "Others" (35.3\%). Specifically, their motivations were 1) modification of the fundamental Barrier-Free national policy in 2011,2) completion of the previous BFBP before 2006, 3) necessity of establishing new "Concentrated-Development Districts" to adapt to urban development, and 4) review of BFBP according to social demands and urban management. Moreover, there was one case in which a railway transportation company required a municipal government to review its previous BFBP (ref BFBP created before 2006). Thus, Lb had a tendency to manage BFBPs systematically in relation to their urban development and national policies.

Table 2. Main selected options of each group regarding the motivations for creating BFBPs

\begin{tabular}{c|c|c|c|c|c}
\hline & $\{9\}$ & $\{4\}$ & $\{5\}$ & $\{12\}$ & $\{1\}$ \\
\hline $\mathrm{La}$ & $\mathbf{8 4 . 1 \%}$ & $9.1 \%$ & $22.7 \%$ & $11.4 \%$ & $18.2 \%$ \\
\hline $\mathrm{Lb}$ & $\mathbf{7 3 . 5} \%$ & $8.8 \%$ & $41.2 \%$ & $35.3 \%$ & $2.9 \%$ \\
\hline $\mathrm{Sa}$ & $\mathbf{4 1 . 4 \%}$ & $\mathbf{4 1 . 4 \%}$ & $22.4 \%$ & $8.6 \%$ & $13.8 \%$ \\
\hline $\mathrm{Sb}$ & $\mathbf{6 6 . 7 \%}$ & $33.3 \%$ & $23.8 \%$ & $9.5 \%$ & $14.3 \%$ \\
\hline $\mathrm{Sc}$ & $38.5 \%$ & $\mathbf{4 2 . 3 \%}$ & $23.1 \%$ & $7.7 \%$ & $15.4 \%$ \\
\hline
\end{tabular}




\subsection{Supportive adviser in proceeding with the creation of BFBPs}

The most supportive adviser for municipal governments to create BFBPs (Figure 3) were; 1) "Experts" (63.9\%), 2) "Consultants" (42.1\%), and 3) "Prefectural governments" (41.5\%). Thus, these results suggest that the supportive roles of prefectural governments are important as well as experts and consultants. This strong tendency can be observed in Sc (Table 3). The municipal governments of Sc were latecomers in introducing BFBPs; thus, it is considered that they required advice from prefectural governments, which had helpful information and advice on BFBPs from other municipal governments in the prefecture.

In addition, individual features were found in $\mathrm{Sa}$, and the third highest percentage of Sa was "Others" (36.2\%). Specifically, their supportive advisers were residents with or without disabilities, organizations for people with disabilities, committee members to create BFBPs, and transportation companies. The municipal governments of Sa were small-scale cities and created BFBPs before 2006; however, they did not renew their own BFBPs after 2006. It can be inferred that they had less experience and information regarding the creation of their BFBPs at that time and required their residents' involvement in their small communities.

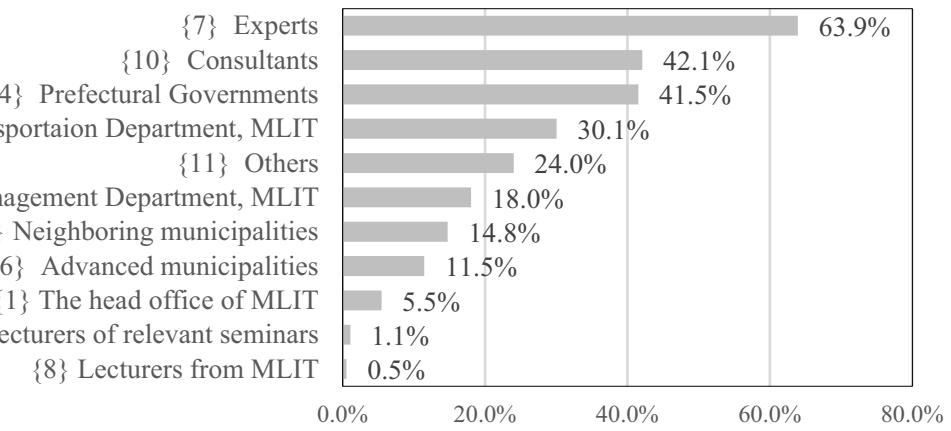

Figure 3. Selected options among all respondents regarding supportive adviser in proceeding with the creation of BFBPs (MA)

Table 3. Main selected options of each group regarding the supportive adviser

\begin{tabular}{c|c|c|c|c|c}
\hline & $\{7\}$ & $\{10\}$ & $\{4\}$ & $\{2\}$ & $\{11\}$ \\
\hline $\mathrm{La}$ & $\mathbf{6 5 . 9} \%$ & $34.1 \%$ & $34.1 \%$ & $31.8 \%$ & $27.3 \%$ \\
\hline $\mathrm{Lb}$ & $\mathbf{7 6 . 5 \%}$ & $58.8 \%$ & $26.5 \%$ & $38.2 \%$ & $23.5 \%$ \\
\hline $\mathrm{Sa}$ & $\mathbf{5 3 . 4 \%}$ & $25.9 \%$ & $46.6 \%$ & $20.7 \%$ & $36.2 \%$ \\
\hline $\mathrm{Sb}$ & $\mathbf{7 6 . 2} \%$ & $57.1 \%$ & $47.6 \%$ & $33.3 \%$ & $4.8 \%$ \\
\hline $\mathrm{Sc}$ & $\mathbf{5 7 . 7} \%$ & $\mathbf{5 7 . 7} \%$ & $\mathbf{5 7 . 7} \%$ & $34.6 \%$ & $7.7 \%$ \\
\hline
\end{tabular}

\subsection{Difficulties of creating their own BFBPS}

Regarding the difficulties of creating their own BFBPs, four stages were revealed, as shown in Figure 4. The primary challenge was 1) coordinating with the entire organization, such as "to negotiate with private sectors" $(55.7 \%)$ and "To create an 
effective internal management organization" (54.1\%); 2) "To obtain sufficient subsidies to create BFBPs" $(39.9 \%)$; 3) management of BFBPs such as "To proceed with the comprehensive procedure in creating BFBPs" (32.2\%) and "To secure sufficient subsidies to manage BFBPs" (30.1\%); and 4) to recognize the significance of BFBPs among the administrative staff and the general public.

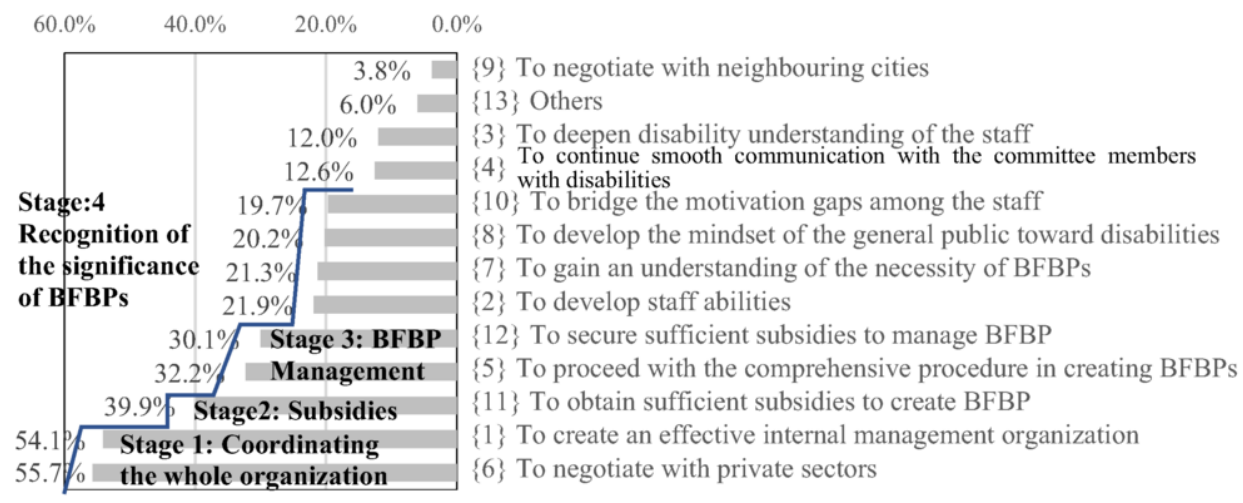

Figure 4 Percentages of the selected options among all respondents regarding the difficulties of creating their own BFBPs (MA)

Regarding the percentages of "To negotiate with private sectors" of $\mathrm{Lb}$ and $\mathrm{Sb}$, they were considerably higher than the second highest percentage of the options (Table 4). Both created BFBPs before 2006 and renewed them after 2006, so that they accumulated much experience. However, they still considered it as the most difficult issue. As described previously, municipal governments can create public/private sectors that manage existing buildings to plan and carry out BF projects based on the BFBPs. This means that municipal governments need to negotiate with the private sector to do so. In addition, gaining the private sector's understanding and agreement to plan and conduct their BF projects is time consuming because of financial issues.

Furthermore, a unique feature was revealed in the second highest percentage of the options for $\mathrm{Sb}$. Sb faced the difficulty "To secure sufficient subsidies to manage BFBPs" more than "To obtain sufficient subsidies to create BFBPs" in their small-scale municipalities.

The percentage of "To proceed with the comprehensive procedure in creating BFBPs" of Sc, which created BFBPs after 2006, was considerably higher than that of the other groups. It appears that this feature derives from their lack of experience compared to $\mathrm{Lb}$ and $\mathrm{Sb}$.

Table 4. Main responses of each group regarding the difficulties to create BFBPs

\begin{tabular}{c|c|c|c|c|c}
\hline & $\{6\}$ & $\{1\}$ & $\{11\}$ & $\{5\}$ & $\{12\}$ \\
\hline $\mathrm{La}$ & $50.0 \%$ & $\mathbf{7 0 . 5} \%$ & $40.9 \%$ & $22.7 \%$ & $25.0 \%$ \\
\hline $\mathrm{Lb}$ & $\mathbf{7 0 . 6 \%}$ & $41.2 \%$ & $41.2 \%$ & $32.4 \%$ & $32.4 \%$ \\
\hline $\mathrm{Sa}$ & $\mathbf{5 0 . 0} \%$ & $48.3 \%$ & $41.4 \%$ & $32.8 \%$ & $32.8 \%$ \\
\hline $\mathrm{Sb}$ & $\mathbf{5 2 . 4 \%}$ & $38.1 \%$ & $33.3 \%$ & $19.0 \%$ & $42.9 \%$ \\
\hline $\mathrm{Sc}$ & $61.5 \%$ & $\mathbf{6 9 . 2} \%$ & $38.5 \%$ & $57.7 \%$ & $19.2 \%$ \\
\hline
\end{tabular}




\subsection{Key factors to promote the quality of BFBPs}

To clarify the key factors that promote the quality of BFBPs, 23 options were classified into five categories: 1) subsidies, 2) support, 3) planning, 4) laws, and 5) human resources (Figure 5). The most important factor was "To create an internal management organization" (73.8\%), which was considered one of the difficulties. Subsequently, a series of subsidies was recognized as an indispensable factor. These results are assumed to be the general tendencies and fundamental features of promoting the quality of BFBPs. Moreover, "To obtain cooperation of residents/organizations with disabilities" (54.1\%), "Consistent relation with local welfare plan" (43.7\%) and "Consistent relation with urban master plan" (42.6\%) were considered as key factors. Simply, municipal governments also recognized the necessity of active public involvement and the above mentioned multidisciplinary perspectives in planning the entire community (Figure 6).

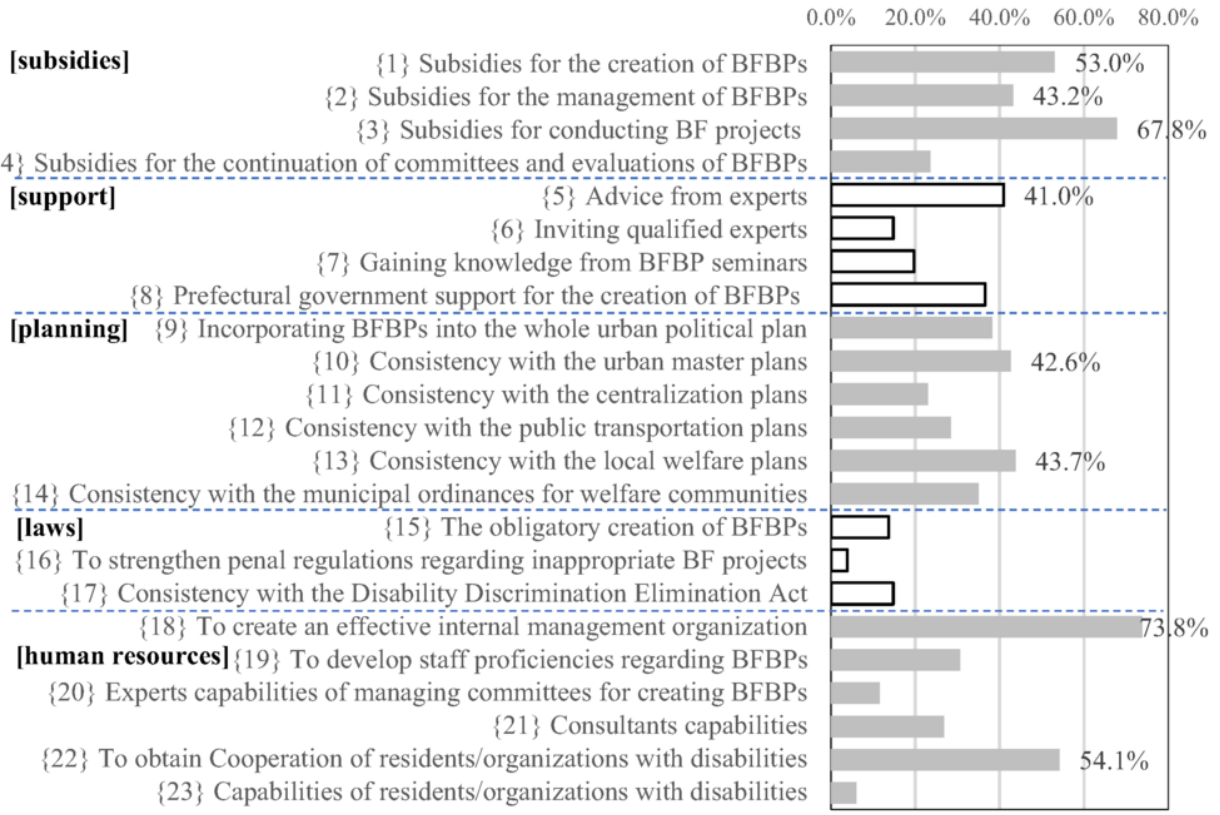

Figure 5 Key factor percentages of the respondents to promote the quality of BFBPs (MA)

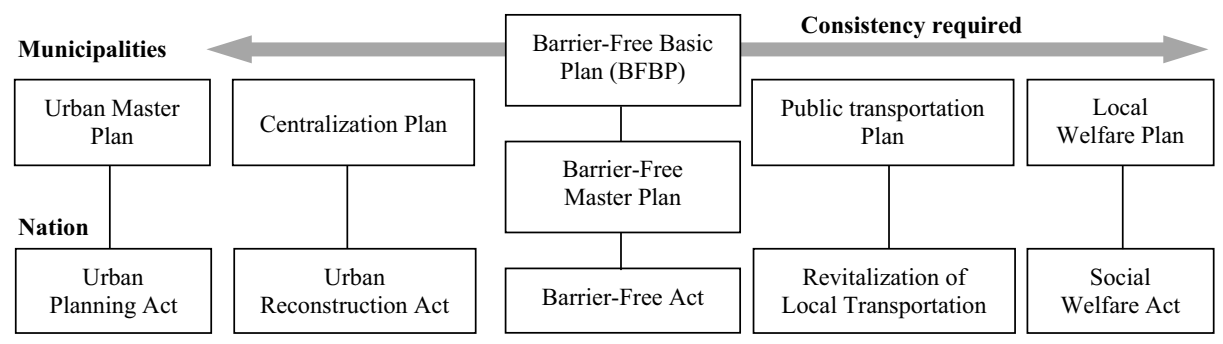

Figure 6 Fundamental framework between related plans regardless of the scale of municipalities 
For the features of each group, La which created BFBPs before 2006 but did not renew them focused on 1) the internal management organization, 2) a series of subsidies and 3) advice from experts. Compared to the above results, La's views were restricted. Sa had similar tendencies to La. However, they selected the options regarding subsidies and also the following options: "To obtain cooperation of residents/organizations with disabilities" (51.7\%) and "Prefectural government supports for the creation of BFBPs" $(48.3 \%)$. It is considered that these features are related to small-scale municipalities. Lb and $\mathrm{Sb}$ recognized "Subsidies for conducting $B F$ projects" as more important than the other three types of subsidies. It is assumed that they are more concerned with the effectiveness of BFBPs; in other words, they expect smooth negotiations with the private sector by securing subsidies for their BF projects. On the other hand, Sc had broader perspectives than those of the other groups, such as "Consistency with the urban master plan" (53.8\%) and "Consistency with the local welfare plan" (50.0\%). These characteristics of Sc, which were latecomers in introducing BFBPs, suggest that the other groups and municipalities that do not have their own BFBPs should consider these perspectives in the future when creating or renewing BFBPs.

Table 5. Five highest percentages of the options of each group regarding key factors to promote the quality of BFBPs

\begin{tabular}{|c|c|}
\hline $\begin{array}{l}\text { La } \\
\text { 1) To create an effective internal management } \\
\text { organization }(86.4 \%) \\
\text { 2) Subsidies for the creation of BFBP }(65.9 \%) \\
\text { 2) Subsidies for conducting BF projects }(65.9 \%) \\
\text { 4) Subsidies for the management of BFBP }(50.0 \%) \\
\text { 5) Advice from experts }(50.0 \%)\end{array}$ & $\begin{array}{l}\text { Sa } \\
\text { 1) To create an effective internal management } \\
\text { organization }(67.2 \%) \\
\text { 2) Subsidies for conducting BF projects }(62.1 \%) \\
\text { 3) Subsidies for the creation of BFBP }(56.9 \%) \\
\text { 4) To obtain Cooperation of residents/organizations } \\
\text { with disabilities }(51.7 \%) \\
\text { 5) Prefectural government supports for the creation } \\
\text { of BFBP }(48.3 \%)\end{array}$ \\
\hline $\begin{array}{l}\text { Lb } \\
\text { 1) To create an effective internal management } \\
\text { organization }(79.4 \%) \\
\text { 2) Subsidies for conducting BF projects }(76.5 \%) \\
\text { 3) To obtain Cooperation of residents/organizations } \\
\text { with disabilities }(61.8 \%) \\
\text { 4) Subsidies for the management of BFBP }(50.5 \%) \\
\text { 5) Consistency with the municipal ordinances for } \\
\text { welfare communities }(47.1 \%)\end{array}$ & $\begin{array}{l}\text { Sb } \\
\text { 1) Subsidies for conducting BF projects }(66.7 \%) \\
\text { 2) To create an effective internal management } \\
\text { organization }(57.1 \%) \\
\text { 3) To obtain Cooperation of residents/organizations } \\
\text { with disabilities }(52.4 \%) \\
\text { 3) Subsidies for the creation of BFBP }(52.4 \%) \\
\text { 5) Advice from experts }(42.9 \%)\end{array}$ \\
\hline $\mathrm{s}$ & $\begin{array}{l}\text { Sc } \\
\text { 1) To create an effective internal management } \\
\text { organization }(73.1 \%) \\
\text { 2) Subsidies for conducting BF projects } \\
\text { 3) To obtain Cooperation of residents/organizations } \\
\text { with disabilities }(61.5 \%) \\
\text { 4) Consistency with the urban master plan }(53.8 \%) \\
\text { 5) Consistency with the local welfare plan }(50.0 \%)\end{array}$ \\
\hline
\end{tabular}

\subsection{Self-evaluation of their own BFBPS.}

To figure out each self-evaluation of BFBPs in terms of continuous management and relation with their communities, seven options were determined (Table 6). Generally, 
the highest percentage of the options was "The municipal government adequately continues to manage the BFBP" $(41.5 \%)$. In particular, $\mathrm{Lb}$ and $\mathrm{Sb}$, which created BFBPs before 2006 and renewed them after 2006, had strong trends toward the continuous management of BFBPs. Moreover, regarding Lb, the percentages of positive relationships with residents $(41.2 \%)$ and local organizations $(55.9 \%)$ relevant to disabilities were higher than those of others. $\mathrm{Sb}$, which were similar to those of $\mathrm{Lb}$, also gained the positive cooperation of regional private sectors $(42.9 \%)$ and integrated the regionality and originality into their BFBPs $(33.3 \%)$.

However, the percentages of each group 1) conducting PDCA cycles and 2) developing the mindset of the general public toward disabilities were low. This suggests that follow-up evaluations after conducting BF projects under BFBPs have been insufficient and the understanding of disabilities is still one of the main issues in communities.

Table 6. Percentages of the options of each group regarding the self-evaluation of their own BFBPs

\begin{tabular}{c|c|c|c|c|c|c|c}
\hline & $\{1\}$ & $\{2\}$ & $\{3\}$ & $\{4\}$ & $\{5\}$ & $\{6\}$ & $\{7\}$ \\
\hline $\mathrm{La}$ & $20.5 \%$ & $6.8 \%$ & $13.6 \%$ & $11.4 \%$ & $34.1 \%$ & $4.5 \%$ & $15.9 \%$ \\
\hline $\mathrm{Lb}$ & $17.6 \%$ & $41.2 \%$ & $55.9 \%$ & $29.4 \%$ & $61.8 \%$ & $26.5 \%$ & $17.6 \%$ \\
\hline $\mathrm{Sa}$ & $32.8 \%$ & $8.6 \%$ & $15.5 \%$ & $10.3 \%$ & $31.0 \%$ & $1.7 \%$ & $6.9 \%$ \\
\hline $\mathrm{Sb}$ & $33.3 \%$ & $38.1 \%$ & $38.1 \%$ & $42.9 \%$ & $47.6 \%$ & $9.5 \%$ & $14.3 \%$ \\
\hline $\mathrm{Sc}$ & $19.2 \%$ & $11.5 \%$ & $19.2 \%$ & $15.4 \%$ & $46.2 \%$ & $11.5 \%$ & $15.4 \%$ \\
\hline Average & $25.1 \%$ & $18.0 \%$ & $25.7 \%$ & $18.6 \%$ & $41.5 \%$ & $9.3 \%$ & $13.1 \%$ \\
\hline
\end{tabular}

$\{1\}$ The BFBP sufficiently considers the regionality and originality of the municipality.

$\{2\}$ The municipal government develops mutual trust with residents with disabilities.

$\{3\}$ Various local organizations are positively involved in creating and managing BFBP.

$\{4\}$ The municipal government obtains positive cooperation from regional private sectors.

$\{5\}$ The municipal government continues to manage BFBP adequately.

$\{6\}$ The municipal government conducts PDCA cycles systematically.

$\{7\}$ The municipal government develops the mindset of the general public toward disabilities.

\section{Discussion}

Based on the results, this section clarifies the characteristics of each group and discusses the measures required according to each feature for the progress in creating and managing BFBPs.

La, which were large-scale municipalities and have not renewed their BFBPs since they created them before 2006, were considered as passive municipal governments toward their BFBPs. Their main motivation to create their own BFBPs was the national policies, such as the "Enforcement/Amendment Act", and their supportive advisers were primarily experts/consultants. "To create an effective internal management organization" was considered to be difficult, but necessary for the quality of BFBPs. In addition, they believe that subsidies were important to 1) create BFBPs and 2) negotiate with private sectors. In contrast, they had a weak relationship with residents and local organizations. These municipal governments need to acquire their residents' 
opinions, and residents should also be more concerned about their outdated BFBPs. Therefore, it is expected that the latest amendment of the Barrier-Free Act will accelerate them to update their own BFBPs.

On the contrary, Lb, which renewed its own BFBPs after 2006, were recognized as forward thinking municipal governments among large-scale municipalities. Their motivation to create and renew their BFBPs was based on the national policies and the adaptation for the next stage of BFBPs, which considered their urban development and social demands. They had difficulties in creating an effective internal management organization and gaining adequate subsidies for the creation of BFBPs. However, their primary challenge was the negotiation with private sectors to make them plan and conduct BF projects of their own existing buildings/facilities. In addition, Lb considered subsidies (from the national government to private sectors) for conducting $\mathrm{BF}$ projects as the most important factor in overcoming difficult negotiations and promoting the quality of BFBPs.

$\mathrm{Lb}$ also valued the cooperation of their residents; they had good relations with them and local organizations. To ensure the effectiveness of BFBPs, municipal governments need to help the local private sector better understand the significance of BFBPs. In addition, the national government should provide financial support for smooth negotiations between municipal governments and the private sector.

Group S were mostly small-scale municipalities (including the six exceptions among Sc) Their motivation for creating BFBPs was mainly the enforcement/amendment of the Barrier-Free Act and to obtain sufficient subsidies from the national government. Their supportive advisers were experts/consultants and prefectural governments. Simply, the national/prefectural governments played a significant role in encouraging small-scale municipal governments to create their own BFBPs.

Sa, which have not updated their own BFBPs, had the fundamental challenge of 1) negotiating with private sectors, 2) creating an effective internal management organization and 3) gaining adequate subsidies for the creation of BFBPs. They had to overcome these basic difficulties and to obtain their residents' cooperation and prefectural support to ensure the quality of BFBPs. In fact, they received conducive advice from their residents on creating BFBPs, however self-evaluation regarding their relationship with residents and local organizations was low. Thus, they did not sustain a positive relationship with each other. The incentives and financial support from the national/prefectural governments to create and manage BFBPs are vital for the municipal governments of Sa. Simultaneously, municipal governments should also make an effort to guide their residents to have active involvement in updating their own BFBPs.

$\mathrm{Sb}$, which renewed their own BFBPs after 2006, revealed a particular feature in the difficulties of creating BFBPs, such as "To secure sufficient subsidies to manage BFBPs". They focused on 1) gaining subsidies for conducting BF projects by public/private sectors under BFBPs and 2) their residents' cooperation for the improvement of BFBPs. In practice, they achieved active cooperation from their residents, local organizations, and regional private sectors in accordance with their selfevaluation of their own BFBPs. It is assumed that their remaining issue is obtaining appropriate subsidies for private sectors that conduct $\mathrm{BF}$ projects to enhance the effectiveness of BFBPs.

Finally, Sc, which created BFBPs after 2006, found it specifically more difficult to proceed with the comprehensive procedure in creating BFBPs than the other groups. 
They prioritized gaining their residents' cooperation regarding the quality of BFBPs; however, their self-evaluation revealed a superficial relationship with their residents. Building a positive relationship is required in the comprehensive procedure for creating BFBPs. On the other hand, they had different views from the other groups. They wanted to be consistent with their urban master plans/local welfare plans to promote the quality of their BFBPs. This feature originated from the small-scale municipalities, however this broad perspective will also be essential for the large-scale municipalities.

\section{Conclusion}

In this study, 1) the barriers and difficulties administrative officers faced in creating BFBPs and 2) the required factors to raise the quality of BFBPs on a practical level were discovered through a quantitative analysis of the questionnaires to 183 municipal governments in Japan, by considering the population scales of municipalities and the establishment year of the BFBP.

First, the national government plays a key role in incentivizing municipal governments to create BFBPs by enforcing/amending the relevant acts and providing subsidies. Therefore, it is expected that the latest amendment of the Barrier-Free Act in preparation for the Tokyo 2020 Olympic and Paralympic Games will encourage municipal governments that do not have their own BFBPs to create them. Furthermore, prefectural governments have an intermediary role of providing information, knowledge, and financial support to their municipal governments, especially for smallscale municipalities.

The difficulties in creating BFBPs were 1) creating an effective internal management organization, 2) negotiating with private sectors, and 3) obtaining a sufficient budget to create BFBPs. Simply, to overcome these challenges, it is essential to have a constructive discussion among internal sections and with private sectors/the national government/their prefectural governments. Moreover, the municipal governments that renewed their own BFBPs after 2006 (Lb, Sb) and the small-scale municipalities (Group S) indicated that their residents' cooperation was important in raising the quality of BFBPs. Therefore, continuous public interest and involvement in creating/managing their own BFBPs led to the building of trusting relationships with their residents and local organizations, such as $\mathrm{Lb}$ and $\mathrm{Sb}$. Furthermore, especially for the municipal governments that renewed their own BFBPs, such as Lb and Sb, negotiations with private sectors to make them plan/conduct BF projects are essential to enhance the effectiveness of BFBPs. Thus, appropriate subsidies for private sectors that conduct BF projects will support the constructive discussion between municipal governments and the private sector.

According to the self-evaluations of BFBP, the PDCA cycle was generally insufficient. It can be assumed that the bottlenecks are "Check" and "Action". The effective methods of inspecting the quality of BFBPs and relevant projects should be further discussed and established.

Finally, the municipal governments that created BFBPs after 2006 suggested that BFBPs should be related to the urban master plans and local welfare plans. They learned from the early comers that connecting BFBPs with other related urban/welfare plans based on the different acts would promote accessibility projects more efficiently and smoothly, compared to having a vertical system. In addition, BFBPs are not only special plans for the elderly and people with disabilities and should be considered 
under their comprehensive urban plans regardless of the scale of the municipalities. Moreover, most municipal governments recognized that the mindset of the general public toward disabilities was insufficient. In that respect, it is considered that discussions of creating BFBPs related to local welfare plans will provide administrative officers and the general public opportunities to cultivate a better understanding of the reality and difficulties in daily lives of people with disabilities.

Therefore, these attempts and measures of BFBPs in Japan, aiming at better accessibility based on the discussions in the fields of architecture, city planning and civil engineering, will improve the accessibility of a whole city and serve as a reference and influence other countries. To keep removing obstacles of existing buildings under BFBPs will bring comfortable cities for everyone, which can help lead to the universal design of cities.

\section{Acknowledgement}

This project was supported by grants in 2018 from the Foundation for Promoting Personal Mobility and Ecological Transportation, Japan. We are grateful to all the administrative officers who cooperated with our surveys.

\section{References}

[1] Takahashi, G., The concept and development for community wellbeing, SHOKOKUSHA Publishing Co., Ltd., Tokyo, 2019. (in Japanese)

[2] Ministry of Land, Infrastructure, Transport and Tourism (MLIT), The survey results of the status of making BFBP based on the Act on Promoting Easily Accessible Public Transportation Infrastructure for the Aged and the Disabled in 2006, https://www.mlit.go.jp/kisha/kisha06/01/011122/02.pdf (accessed 16 August 2020), 2006 (in Japanese)

[3] Ministry of Land, Infrastructure, Transport and Tourism (MLIT), The lists of the municipal governments which have BFBP, https://www.mlit.go.jp/sogoseisaku/barrierfree/content/001340561.pdf (accessed 16 August 2020), 2020 (in Japanese)

[4] Ministry of Land, Infrastructure, Transport and Tourism (MLIT), Barrier-Free and Universal Design, https://www.mlit.go.jp/sogoseisaku/barrierfree/index.html (accessed 16 August 2020), 2020 (in Japanese)

[5] Ministry of Land, Infrastructure, Transport and Tourism (MLIT), The survey of the status of creating BFBP, https://www.mlit.go.jp/sogoseisaku/barrierfree/sosei_barrierfree_mn_000007.html (accessed 16 August 2020), 2020 (in Japanese)

[6] Fujimura, Y., The status and issues of making Barrier-Free Basic Plan based on the Act on Promoting Easily Accessible Public Transportation Infrastructure for the Aged and the Disabled, Journal of Japanese Association for an Inclusive Society, Vol. 4, No.1 (2002), 1-12 (in Japanese)

[7] Suzuki, Y., Study on Future of Citizen's Participation toward Barrier-Free Transportation: Through a case of activities in Himeji City, Journal of Japanese Association for an Inclusive Society, Vol. 6, No.1 (2004), 31-37 (in Japanese)

[8] Yamada, M., Users Involvement and its effect of the education for government staff with the process to establish the Basic plan under the Transportation Accessibility Improvement Law, Infrastructure planning review 23 (2006), 1057-1064 (in Japanese)

[9] Isobe, T., Proposal of Method of Flexibility Settling on Fundamental Plan on Barrier-Free, Proceedings of infrastructure planning 40 (2009), 191-194 (in Japanese)

[10] Fujiwara, S., Kitano, M., Nishimori, E. and Adachi, K., Evaluation of Barrier-Free Action Plan in the Osaka Bentencho area for disabled persons, AIJ Kinki Chapter research meeting, Planning section 56 (2016), 69-72 (in Japanese)

[11] Sato, K., Ishiguro, A., Odate, K., Shibaoka, A. and Watabe, T., Current status and problems of transport Barrier-Free improvement in administrative boundaries area: Case of sidewalk around JR Iidabashi 
station across 3 municipalities, Proceedings of the General Meeting of the Association of Japanese Geographers (2017), 100204 (in Japanese)

[12] Ishizuka, Y., Takahashi, F., Nitta, Y., and Mihoshi, A., Study of the Effects of Continued Universal Design For Community Development, Journal of Japan Society of Civil Engineers, Vol. 72, No.5 (2016), 1155-1166 (in Japanese)

[13] Ministry of Land, Infrastructure, Transport and Tourism (MLIT), The annual survey results of the status of making BFBP, https://www.mlit.go.jp/sogoseisaku/barrierfree/sosei_barrierfree_mn_000007.html (accessed 21 August 2020), (in Japanese) 